\title{
RHODOMYRTUS TOMENTOSA: A PHYTOCHEMICAL AND PHARMACOLOGICAL REVIEW
}

\author{
HAZRULRIZAWATI ABD HAMID*, SENAIT SILESHI ZEYOHANNES ROZIASYAHIRA MUTAZAH, \\ MASHITAH M YUSOFF
}

Department of Chemistry, Faculty of Industrial Sciences \& Technology, Universiti Malaysia Pahang, Lebuhraya Tun Razak, 26300 Gambang Kuantan, Pahang, Malaysia. Email: hazrulrizawati@ump.edu.my

Received: 12 May 2016, Revised and Accepted: 23 September 2016

\section{ABSTRACT}

Rhodomyrtus tomentosa is a common wood, prevalent in areas with undemanding soil conditions and resistant toward pests and diseases. The plant can be found in China, Taiwan, Philippines, Malaysia, Indonesia, and Vietnam. Literature and artwork indicate that $R$. tomentosa played an important holistic role in the daily lives of several ancient cultures, providing medicinal benefits. $R$. tomentosa exhibits a wide spectrum of pharmacological effects and has been used to treat colic diarrhea, wounds, heartburn, abscesses, gynecopathy, and as a pain killer. $R$. tomentosa was used in traditional Chinese medicine to treat urinary tract infection. 42 compounds have been isolated from this plant and structurally elucidated. They comprise phloroglucinol, flavonoid, terpenoid, anthracene glycoside, tannin, and other compounds. Rhodomyrtone, a member of the acylphloroglucinols demonstrated a significant activity against a wide range of Gram-positive bacteria. Rhodomyrtone exhibited both antimicrobial and anti-infective activities. Several biological activities have been documented as antibacterial, antifungal, antimalarial, osteogenic, antioxidant, and anti-inflammatory $R$. tomentosa has been studied extensively for alternative antimicrobial agents. Although rhodomyrtone exhibited potential activity with a very low minimum inhibitory concentration value, the mechanisms of action of this compound are still unclear. Furthermore, toxicity studies on it extract to validate pharmacological activities are required.

Keywords: Rhodomyrtus tomentosa, Kemunting, Phytochemical, Pharmacological, Biological activities, Chemical constituents.

(C) 2017 The Authors. Published by Innovare Academic Sciences Pvt Ltd. This is an open access article under the CC BY license (http://creativecommons. org/licenses/by/4. 0/) DOI: http://dx.doi.org/10.22159/ajpcr.2017.v10i1.12773

\section{INTRODUCTION}

Nature, and especially plant life, has long been a sought out source for new medications. These efforts have brought about the use of a large number of medicinal plants with curative properties against different diseases. In recent years, nearly $80 \%$ of the world's population relies on traditional medicines for primary health care, and most of these traditional medicines involve the utilization of plant extracts. As a result of the unmatched availability of chemical diversity, standardized plant extracts and pure compounds isolated from the extracts offer a broad opportunity for the identification of new drugs [1]. Plant extracts contain different bioactive compounds that play a key role in treating illnesses. Bioactive compounds in plants are described as secondary plant metabolites that elicit pharmacological or toxicological effects in humans and animals [2]. The utilization of herbal medicines in Asia speaks to a long history of human interaction with nature. An extensive variety of substances is found from different traditional medicinal plants which have an ability to treat chronic and infectious diseases [3]

Recently, Rhodomyrtustomentosa wasidentified as one of the 240 "Neglected and Underutilized Crop Species" of Vietnam, China, Thailand, and Cambodia, by the scientific project "Agrofolio" (www.Agrofolio.eu/db) Historically, R. tomentosa has been used in traditional Vietnamese, Chinese, and Malaysian medicine to treat diarrhea or dysentery, as well as stimulate the immune system [4]. Recently, the ethanol extract of $R$. tomentosa leaves and rhodomyrtone, its principle compound, have been demonstrated to have excellent antibacterial activity against Gram-positive bacteria [5]. However, little information is available in the literature concerning the chemical constituents and pharmacological activity of $R$. tomentosa. This review article explores the ethnopharmacological and pharmacological activities and phytochemicals, which provide evidence of a potent drug with potential application in treating a variety of illnesses.

\section{BOTANY}

R. tomentosa, a member of the Myrtaceae family, is an evergreen shrub native to Southeast Asia, where it grows in abundance with rose-pink flowers and dark-purple edible bell-shaped fruits [6]. It prefers natural light and is relatively undemanding with regards to soil conditions. In addition, it is low maintenance because it is seldom bothered by pests and diseases [7]. The stem, leaves, and fruits of the whole plant can be used as medical materials. The word Rhodomyrtus is derived from the Greek words Rhodon for red and myrtose for myrtle. In different areas, $R$. tomentosa is also known by the names Australia myrtle, Ceylon hill cherry, Ceylon hill gooseberry, Downy myrtle, Downy rose myrtle, fluffy blueberry, hill guava, Isenberg Bush, rhodomyrtus, rose myrtle, and tomentose rose myrtle [8].

R. tomentosa usually grows up to a length of $12 \mathrm{ft}$, with 3 trunks from the base. It has piercing leaves that are $2-3^{\prime \prime}$ long [9]. The name tomentose is given to this species due to the nature of its leaves, which have a glossy green appearance on the upper side of the leave and a dense, soft, hairy appearance on the underside [10]. Each $R$. tomentosa flower has five petals in clusters of two or three. The flowers are $2.5-3 \mathrm{~cm}$ in diameter and are tinged white on the outside with purplish-pink inside [9]. The 10-15 mm long blueberry-like fruits are edible and are well known for their sugar, vitamin, and mineral contents. The fruit is an ellipsoid berry that measures $1-1.5 \mathrm{~cm}$ in diameter, with a persistent calyx. Unripe fruits have green skin and an astringent taste. The berry turns to a purplish black when ripe, and the pulp is purplish, soft, and sweet. The berries contain many deltoid seeds that measure $1.5 \mathrm{~mm}$ in diameter and are located in 6 pseudo-locules divided by thin false septa [8]. The sweet and ripe fruits are consumed fresh or made into pies, tarts, jellies, preserves, and jams, or they are used in salads. In Vietnam, the fruits are used to produce a wine called routusim [8].

Two varieties are distinguished, viz., the $R$. tomentosa var. tomentosa (synonym, Myrtus canescens Lour) variety occurs in South-East Asia, Southern China, and Indo-China. This variety has tomentosa leaves that are whitish, apex-rounded, or obtuse, not apiculate. The veins are not reticulate, and the pedicels are 1-2.5 $\mathrm{cm}$ long. The $R$. tomentosa var parviflora (Alston) A.J. Scott (synonym, Rhodomyrtus parviflora Alston) variety occurs in India and Sri Lanka. It has tomentosa leaves that are cream or yellowish and have apiculate apexes. The veins are reticulate, and the pedicels are $<1 \mathrm{~cm}$ long [11]. 


\section{ETHNOPHARMACOLOGY}

Ethnomedicinal studies on $R$. tomentosa have been documented by several researchers. All parts of this plant (leaves, roots, buds, and fruits) have been used traditionally in Vietnamese, Chinese, and Malaysian medicine [4]. The tender leaves have traditionally been used to treat colic, dysentery, abscesses, and sepsis. It has been documented for use to treat tuberculosis [12], colic diarrhea [13], abscesses, hemorrhage, and gynecopathy [14]. It also has been used in the Thai traditional medicine as antipyretic, antidiarrheal, and antidysentery medicine [15] and in traditional Chinese medicine for the treatment of urinary tract infections [14]. In Singapore, the Chinese have used the leaves as a pain killer, the roots to treat heartburn, and the seeds as a tonic for digestion and to treat snake bites, and in Indonesia, the leaves are used to treat wounds [8]. R. tomentosa is reportedly sold as an herbal supplement in America [16].

\section{PHYTOCHEMICAL ANALYSIS AND NUTRITIONAL COMPOSITION}

Detailed phytochemical and nutritional analyses of $R$. tomentosa had been carried out. A $150 \mathrm{~g}$ serving of sim fruit contained high levels of dietary fiber (69.94-87.43\% of Reference Daily Intake [RDI]), $\alpha$-tocopherol (38.90-51.87\% RDI), manganese (>100\% RDI), and copper $(44.44 \% \mathrm{RDI})$, but it contained low levels of protein $(2.63 \%$ RDI), lipids (1.59-3.5\% RDI), and sugars (5.65\% RDI). The predominant fatty acid in the sim fruit sample was linoleic acid $(75.36 \%$ of total fatty acids) [7]. Extraction from $R$. tomentosa sim fruits revealed a total phenolic level of $49.21 \pm 0.35 \mathrm{mg}$ gallic acid equivalent/g dry weight [7] Compared with other fruits, this result demonstrates that $R$. tomentosa has a similar total phenolic content as berries [17]. The discoveries reported in the study highlight the potential of $R$. tomentosa as a new source of health-promoting compounds such as dietary fibers, essential fatty acids, and phenolic compounds. A total of 19 phenolic compounds were tentatively characterized, including stilbenes and ellagitannins as major components, followed by anthocyanins, flavonols, and gallic acid. Piceatannol, a promising health-promoting stilbene component, was the major phenolic compound found in R. tomentosa fruits [18].

In a similar study, the extraction of the dried fruits with trifluoroacetic acid-methanol (MeOH) mixture (1:99) and further purification with highperformance liquid chromatography (HPLC) and column chromatography resulted in the identification of six major anthocyanins, including cyanidin-3-0-glucoside, peonidin-3-0-glucoside, malvidin-3-0-glucoside, petunidin-3-0-glucoside, delphinidin-3-0-glucoside, and pelargonidin3-glucoside [19]. The study confirmed the six anthocyanins previously identified previously were reported for the first time from $R$. tomentosa [20]. Cyanidin-3-0-glucoside is the major anthocyanins formed [20].

The crude extracts from four solvents (water, $\mathrm{MeOH}$, chloroform $\left[\mathrm{CHCl}_{3}\right]$, and petroleum ether) were further incorporated into thin layer chromatography/HPLC/gas chromatography-mass spectrometry (GCMS) techniques to separate the bioactive compounds. Alkaloids, phenols, and terpenoids have been identified in all the solvent extracts. The compounds identified in the water extract were malic acid, gallic acid, caffeic acid, dihydrocaffeic acid, quinic acid, octadecenoic acid, galloyl glucose, and brevifolin carboxylic acid. The study reported that the total phenolic content was much higher in the water extract than in the other extracts. The HPLC analysis also showed the presence of quercetin, tannic, and gallic acids [9].

According to Wu et al. [21], the dried berry was extracted with $95 \%$ ethanol-petroleum ether and further purified with $40 \%$ ethanol. This extract from $R$. tomentosa berries was rich in flavonoids and possessed more than 20 times the total flavonoid content compared to cranberries [21]. Using ultra-performance liquid chromatography-time of flight-MS techniques, six flavonoids from the extract were chemically profiled and were identified as kaempferol, quercetin-7,4'-diglucoside, dihydromyricetin, vitexin, myricetin, and quercetin. The identification of quercetin from the $\mathrm{MeOH}$ extract of the aerial part of the plant has also been reported in another study by Tung et al. [22].

\section{ISOLATED CHEMICAL CONSTITUENTS}

Phytochemical investigations of the leaf, fruit, and root extracts of R. tomentosa have led to the isolation of phloroglucinols, flavonoids, terpenoids, anthracene glycosides, tannins, and other compounds (Table 1). The data obtained from the high-resolution electron ionization MS spectrum showed that rhodomyrtosone B is a structural isomer of rhodomyrtone. The $\beta$-triketone moiety, which results in the unique structure of these compounds, is rare but commonly found in the Myrtaceae family. Of these compounds, rhodomyrtosone A is reported to be the first example with a novel bisfuran fused-ring skeleton and rhodomyrtosone $\mathrm{D}$ is the first to be identified as a leptospermone derivative [23]

Further investigation by Hiranrat and Mahabusarakam [23] resulted in the isolation of two phloroglucinols named tomentosone A (23) and tomentosone $\mathrm{B}$ (24) from the $\mathrm{CHCl}_{3}$ extract of the leaves. Each of these phloroglucinols was shown to contain six continuous novel hexacyclic rings, and the structure is novel to science. The elucidation of their structures from two-dimensional nuclear magnetic resonance spectroscopy and further correlations made in the study suggested that tomentosone B is a diastereomer of tomentosone A [24]. Most isolated flavonoids contain the galactoside and glucoside sugar moiety.

\section{PHARMACOLOGICAL ACTIVITIES}

A few studies have been carried out to identify possible biological activities of these compounds, as there is a paucity of over 25 years since the first study was reported in 1975. In early 2000, active molecules were identified, and different extracts of the different parts of the plant, fractions, and isolated compounds were tested for antibacterial, antimalarial, antifungal, antioxidant, anti-inflammatory, and estrogenic activity. Currently, no toxicity profiling of the crude extracts was reported except for rhodomyrtone. However, most publications confirmed that $R$. tomentosa has positive against Grampositive bacteria.

\section{ANTIBACTERIAL ACTIVITY}

Crude ethanolic extract from $R$. tomentosa demonstrated good antibacterial activity against Gram-positive bacteria. Isolation of rhodomyrtone from the ethanolic extract using bioassayguided fractionation revealed the active compound to be a type of acylphloroglucinol that is a natural antibiotic for cutaneous staphylococcal infections. The compound demonstrated powerful in vitro activity against a broad range of Gram-positive bacteria, including antibiotic-resistant strains [32]. The crude ethanol extract and purerhodomyrtone showed substantial antibacterial activity against Gram-positive bacteria, viz., including Bacillus cereus, Bacillus subtilis, Enterococcus faecalis, Staphylococcus aureus, methicillinresistant S. aureus, Staphylococcus epidermidis, Streptococcus gordonii, Streptococcus mutans, Streptococcus pneumoniae, Streptococcus pyogenes, and Streptococcus salivarius [5]. Further, rhodomyrtone exhibited stronger antibacterial activity than vancomycin. Rhodomyrtone has shown minimum inhibitory concentration (MIC) values 2-3 times lower and minimum bactericidal concentration values 160-320 times lower than those of vancomycin. As rhodomyrtone has not demonstrated bacteriolytic activity toward pathogens, a further study was conducted to show that the antibacterial effect of rhodomyrtone is due to the inhibition of $S$. pyogenes toxin via the alteration of the metabolic pathway of the bacterium [32]. Similarly, the study reported that rhodomyrtone has good anti-infective activity because it inhibits the expression of the $S$. pyogenes fibronectinbinding protein, glyceraldehyde-3-phosphate dehydrogenase, disabling S. pyogenes from adhering to mammalian cells and mucosal surfaces.

On the other hand, an additional study reported that rhodomyrtone is very effective against $S$. aureus, with a MIC value of $0.5 \mu \mathrm{g} / \mathrm{ml}$, which is close to that of vancomycin. However, the study challenges the use of rhodomyrtone as an alternative in treating cutaneous staphylococcal 
Table 1: Isolated compounds from $R$. tomentosa

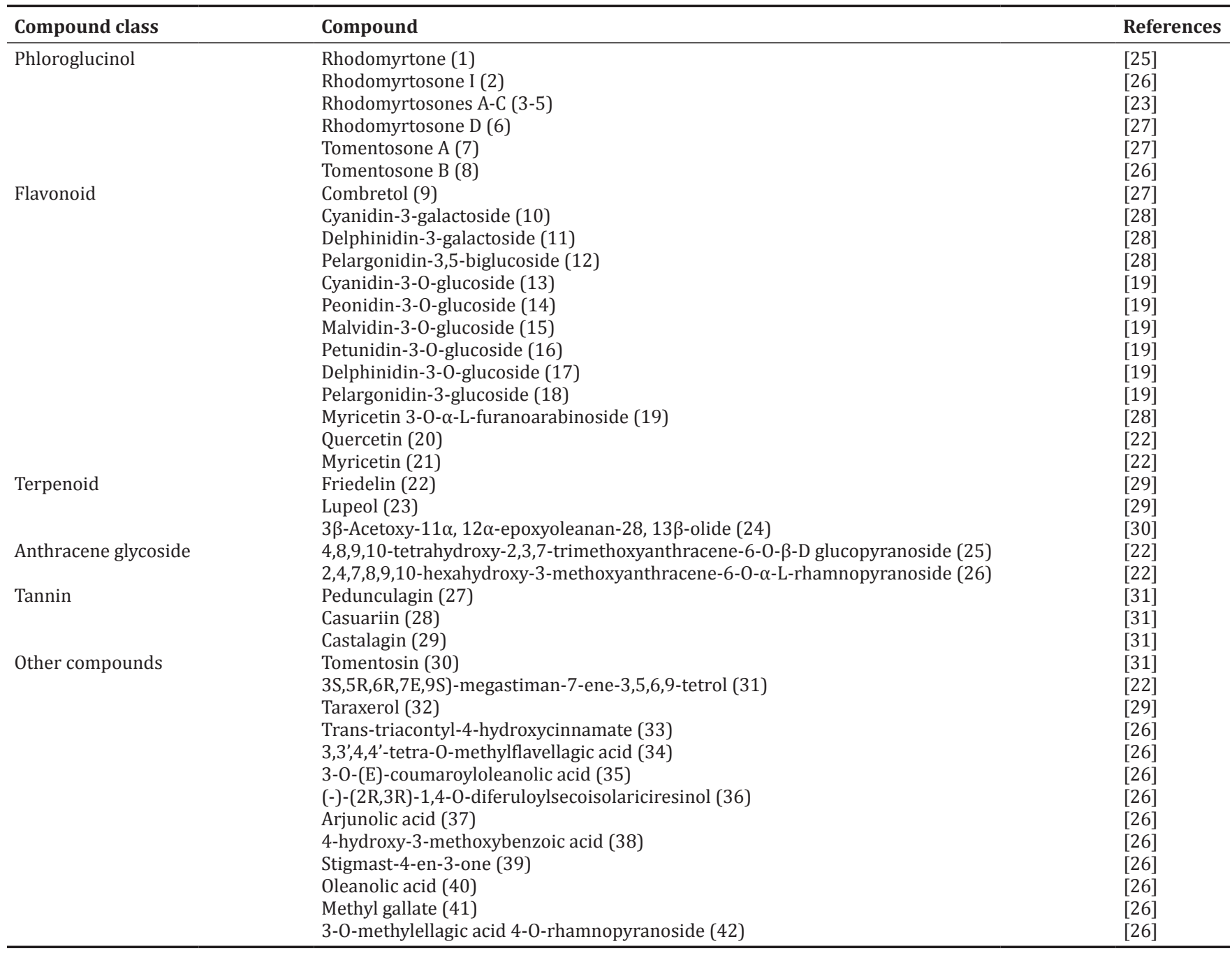

R. tomentosa: Rhodomyrtus tomentosa

infections [33]. The same study assessed the antibacterial activity of the crude ethanolic extract of $R$. tomentosa on staphylococci isolated from acne lesions, and the authors reported antibacterial activity against all isolated coagulase-positive and coagulase-negative staphylococci. Based on their previous study, the same authors conducted further investigations on the antibacterial activity of the ethanolic extract of the plant and rhodomyrtone against Propionibacterium acnes. These results revealed that both the ethanolic extract and rhodomyrtone exhibited good antibacterial activity. As both extract and rhodomyrtone showed very low toxicity on skin cells, the researchers proposed them as potential candidates for development as acne therapeutic agents [34].

The ethanolic crude extract of $R$. tomentosa leaves was tested for its antibacterial activity against 65 samples of $B$. cereus previously isolated from foods. The crude extract produced large inhibition zones (10.00-18.00 mm) against all tested isolates. The study found that the extract could affect both cells and endospores [35] and suggested the use of the extract as a food preservative or food additive agent for controlling the growth of the pathogen and reducing its incidence. It is believed that the extract would not compromise the safety of food. A similar study assessed the effect of the crude ethanol extract of $R$. tomentosa leaf and its isolate, rhodomyrtone, on 47 clinical isolates of $S$. pyogenes isolated from tonsillitis/pharyngitis patients. The crude extract and its isolate, rhodomyrtone, have shown a significant antibacterial activity against 47 and 14 clinical isolates, respectively [36]. The study further reported that the extract has no effect on bacterial cell lysis at all concentrations.
Rhodomyrtone displayed good activity against biofilm-forming and capsulated bacteria, including S. epidermidis ATCC 35984 (biofilmpositive) and Streptococcus pneumonia (capsule-positive). Saising et al. [37] suggested that rhodomyrtone had significant effects on both biofilm formation and the survival of the organisms in the established biofilms. Hence, rhodomyrtone is reported to have the potential for further drug development for the treatment of biofilm-forming staphylococcal infections.

Rhodomyrtone isolated from the ethyl acetateleaf extract of $R$. tomentosa showed a significant antibacterial activity against Escherichia coli and S. aureus [25]. S. aureus was incubated with rhodomyrtone at $0.5 \times \mathrm{MIC}$ $(0.25 \mu \mathrm{g} / \mathrm{ml})$ to assess the susceptibility of rhodomyrtone-treated cells compared with untreated cells at different concentrations of oxidants $\left(\mathrm{H}_{2} \mathrm{O}_{2}\right)$ in vitro. The results show that the untreated normal $S$. aureus cells had a better rate of survival than the cells that were treated with rhodomyrtone as a result of the reduced pigmentation of the cells after incubation with rhodomyrtone [38]. The authors also indicated that the bacterial cell membrane and subsequent cell lysis were not the main target of rhodomyrtone, as the compound had no significant effect on either of them [38].

\section{ANTIFUNGAL ACTIVITY}

Jeenkeawpieam et al. [39] reported that endophytic fungi from $R$. tomentosa can be a good source of potential antifungal natural 
(1)

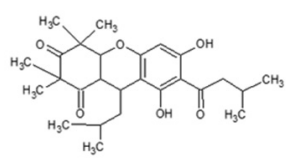

(3)

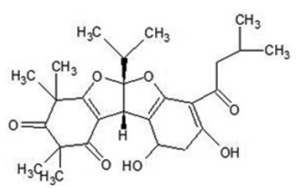

(5)

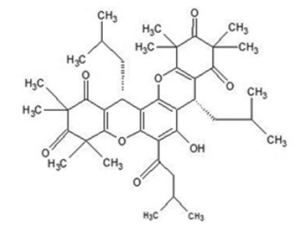

(7)

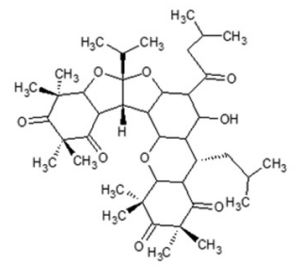

(9)

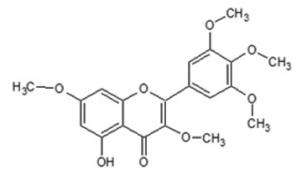

(11)

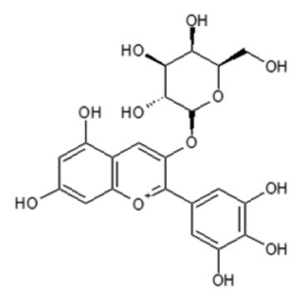

(13)

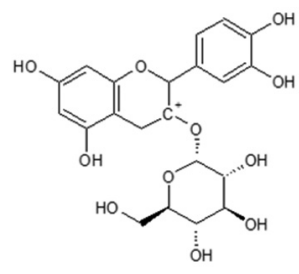

(2)

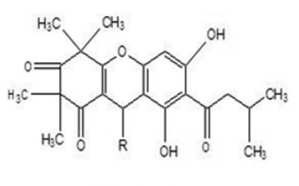

(4)

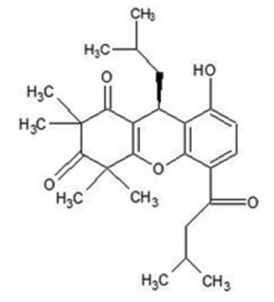

(6)

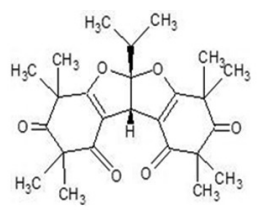

(8)

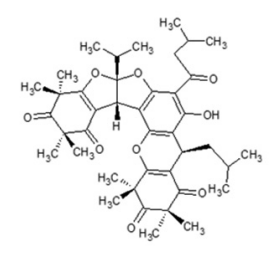

(10)

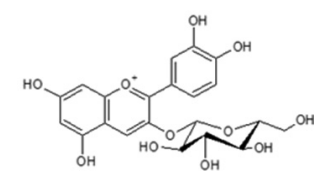

(12)

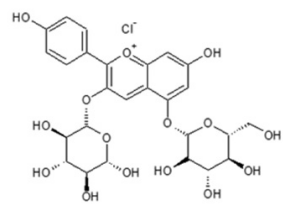

(14)

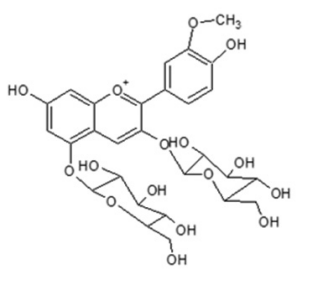

(15)

(16)
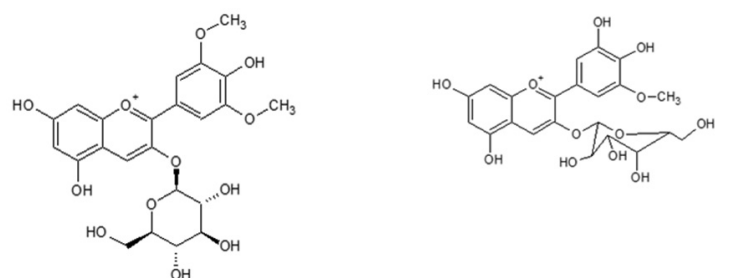

(17)

(18)

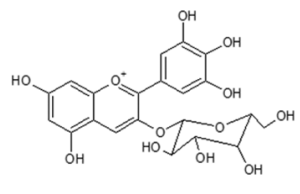

(19)

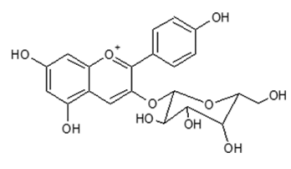

(20)<smiles>N#COc1c(-c2cc(O)c(O)c(O)c2)oc2cc(O)cc(O)c2c1=O</smiles>

(21)

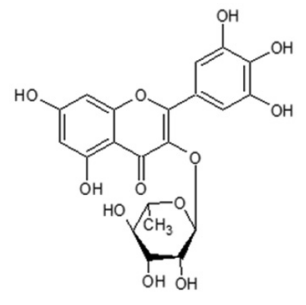

(23)

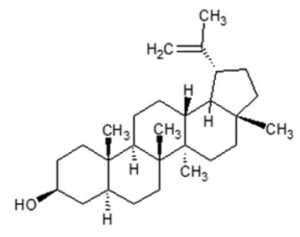

(25)

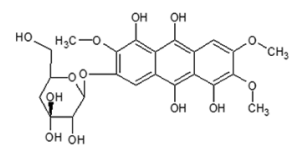

(27)

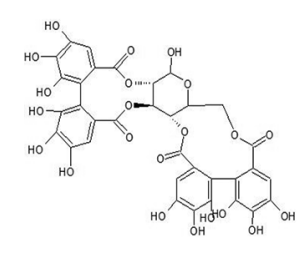<smiles>O=C1C(O)=C(c2ccc(O)c(O)c2)c2oc3cc(O)cc(O)c3c(=O)c21</smiles>

(22)

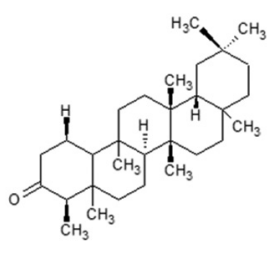

(24)

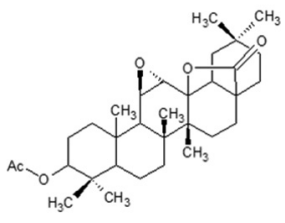

(26)

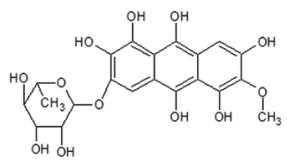

(28)

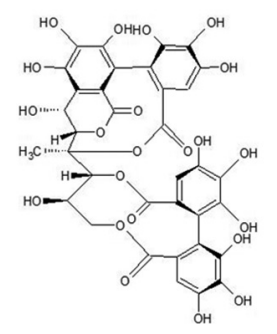


(29)

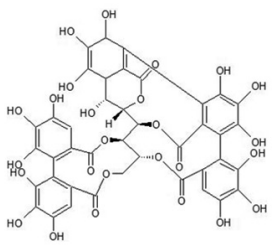

(31)<smiles>CC(O)/C=C/[C@]1(O)C(C)(C)C[C@H](O)C[C@@]1(C)O</smiles>

(33)

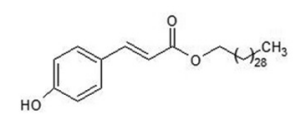

(35)

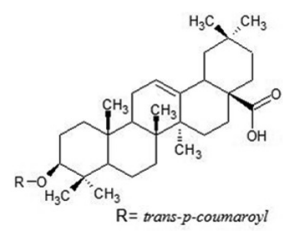

(37)

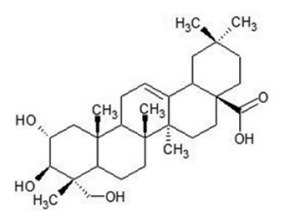

(30)
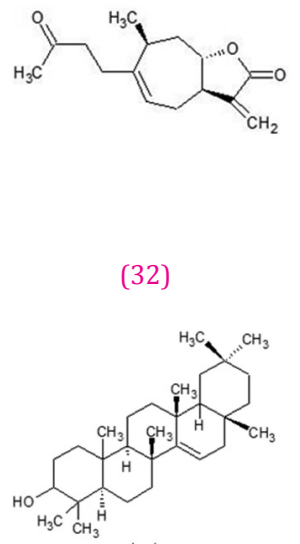

(34)<smiles></smiles>

(36)

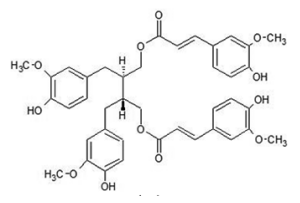<smiles>COc1cc(C(=O)O)ccc1O</smiles>

products. Total 213 fungi isolated from $R$. tomentosa were tested against five strains of human pathogenic fungi including Candida albicans, Cryptococcus neoformans, Microsporum gypseum, and Penicillium marneffei. A total of 349 extracts (56.6\%) from 177 isolates showed a antifungal activity against at least one test fungus. Among the three types of extracts, the $\mathrm{CHCl}_{3}$ extracts of $R$. tomentosa were the most active. Results of the study enabled selection of many potential endophytic fungi from $R$. tomentosa that had strong antifungal activity against various human pathogens. The results indicated that the $R$. tomentosa extract was a good source for endophytic fungi that produce antifungal natural products.

At a concentration of $200 \mu \mathrm{g} / \mathrm{ml}$, the ethanolic extract of $R$. tomentosa leaves exhibited antifungal activity against three pathogenic fung (Bipolaris setariae, C. oryzae, and R. oryzae-sativa) of rice plants with mycelial inhibition above 50\% [40].

\section{ANTIMALARIAL ACTIVITY}

In general, there are a limited number of studies on $R$. tomentosa plant extracts and their isolates in regards to antimalarial activity compared to the number of studies on their antibacterial activities. The two phloroglucinols, tomentosone A and B, were assessed for their activity against the growth of chloroquine-sensitive and chloroquineresistant strains of the malaria parasite, Plasmodium falciparum. While tomentosone A inhibited the growth of both the sensitive and resistant strains, insignificant inhibitory activity was observed for tomentosone B [24].

\section{ANTIOXIDANT ACTIVITY}

Wu et al. [21] investigated the antioxidant activity of the full flavonoid extract of $R$. tomentosa berries using in vivo and in vitro assays. The study revealed that the flavonoid-rich extract from $R$. tomentosa berries has remarkable antioxidant activities in all the reported tests. The results are reported as effective concentration of the extracts was used and ascorbic acid, as a control (Table 2).

The above study reported that the inhibitory effect of the flavonoidrich extract on lipid peroxidation is stronger than that of the control butylated hydroxytoluene. In addition, the extract exhibited in vivo antioxidant ability by affecting the production of free radicals during aerobic respiration and lipid peroxidation. A study by Maskam [9] demonstrated that the $\mathrm{MeOH}$ and water extracts of $R$. tomentosa fruits showed higher scavenging activities than the $\mathrm{CHCl}_{3}$ and petroleum ether extracts of the fruits. The $\mathrm{IC}_{50}$ values of the $\mathrm{MeOH}$ and water extract were found to be $107 \mathrm{l}$ and $154 \mu \mathrm{g} / \mathrm{ml}$, respectively. Similarly, the FRAP assay indicated that $R$. tomentosa extracts have strong antioxidant activity, and all extracts were shown to have significantly weaker chelating ability than the control ethylenediaminetetraacetic acid in a metal chelating ability assay [9].

The acetone extract of $R$. tomentosa leaves significantly inhibited the generation of lipid peroxides with an inhibition capacity of $0.93 \mathrm{mM}$ gallic acid at $100 \mu \mathrm{g} / \mathrm{mL}$ (41). The FRAP assay indicated that the extract has the strong reducing ability at 2.7 and 3.0 times greater than that of the gallic acid and ellagic acid, respectively. The extract showed good chelating activity of ferrous ions. An in vivo test on carbon tetrachlorideinduced oxidative stress in Swiss albino mice revealed that the extract has protective effects by decreasing the enzyme activities of superoxide dismutase (SOD), catalase (CAT), and glutathione peroxidase in the blood, liver, and kidneys of the model mice [41].

Anthocyanins extracted from the dried fruits of $R$. tomentosa showed a significant antioxidant activity. In particular, DPPH, ABTS radicalscavenging activities, and oxygen radical absorbance capacity tests (in $\mu \mathrm{mol}$ trolox equivalents $/ \mathrm{mg}$ ) of the anthocyanin extract showed greater antioxidant activities than ascorbic acid [19] (Table 3). Good antioxidant activity observed for the $R$. tomentosa fruit extracts can be attributed to its high content of vitamin $C$ and vitamin $E$, as these vitamins are known for their hydrophilic and lipophilic antioxidant properties, respectively [7].

The aqueous alcoholic extract of $R$. tomentosa leaves has shown ulcer healing and protective abilities comparable to that of omeprazole in acetic acid-induced gastric ulcers in rats. Likewise, a $400 \mathrm{mg} / \mathrm{kg}$ dose of the extract had a significant ability to enhance CAT and SOD, as well as decrease lipid peroxidation, in a manner similar to that of omeprazole at $20 \mathrm{mg} / \mathrm{kg}$ [42].

\section{ANTI-INFLAMMATORY ACTIVITY}

The MeOH extract from $R$. tomentosa leaves showed significant in vitro and in vivo anti-inflammatory effects, by inhibiting the production of inflammatory mediators (nitric oxide, $\mathrm{NO}$ and prostaglandin, $\mathrm{PGE}_{2}$ ) [16]. Jeong et al. [16] reported that the methanolic extract of $R$. tomentosa can clearly suppress the production of $\mathrm{NO}$ and $\mathrm{PGE}_{2}$ in lipopolysaccharideactivated RAW264.7 cells and peritoneal macrophages in a dosedependent manner. Immunoblotting and immunoprecipitation analyses, as well as a kinase assay with mRNA, whole cell extract, 
Table 2: Radical scavenging activity $\left(\mathrm{EC}_{50}\right)$ of the flavonoid-rich extract with ascorbic acid as control

\begin{tabular}{|c|c|c|c|}
\hline Assay & $\begin{array}{l}\mathrm{EC}_{50} \text { of the flavonoid-rich } \\
\text { extract }(\mu \mathrm{g} / \mathrm{mL})\end{array}$ & $\begin{array}{l}\mathrm{EC}_{50} \text { of ascorbic } \\
\text { acid }(\mu \mathrm{g} / \mathrm{mL})\end{array}$ & Remark \\
\hline DPPH radical scavenging assay & $10.97 \pm 0.18$ & $8.03 \pm 0.11$ & Strong scavenging activity \\
\hline $\begin{array}{l}\text { Hydroxyl radicals }(-\mathrm{OH}) \text { scavenging } \\
\text { assay }\end{array}$ & $217.73 \pm 3.46$ & $116.37 \pm 1.40$ & $\begin{array}{l}\text { Radical scavenging activity of flavonoid-rich extract } \\
\text { increases with the increase of concentration }\end{array}$ \\
\hline $\begin{array}{l}\text { Superoxide radical }\left(\mathrm{O}_{2-}\right) \text { scavenging } \\
\text { assay }\end{array}$ & $214.83 \pm 6.54$ & $60.55 \pm 1.35$ & $\begin{array}{l}\text { A more than three-fold concentration of the extract } \\
\text { was required to be as effective as ascorbic acid }\end{array}$ \\
\hline FRAP assay & $28.67 \pm 1.37$ & $13.75 \pm 0.88$ & Relatively higher reducing power than other studies \\
\hline
\end{tabular}

FRAP: Ferric-reducing antioxidant power, DPPH: 1,1-diphenyl-2-picryl-hydrazyl

Table 3: Antioxidant activities of anthocyanin extracted from $R$. tomentosa fruits and the control sample, ascorbic acid

\begin{tabular}{|c|c|c|c|c|}
\hline Sample & $\begin{array}{l}\text { DPPH radical-scavenging } \\
\text { activity }(\mu \mathrm{g} / \mathrm{mL})\end{array}$ & $\begin{array}{l}\text { ABTS radical-scavenging } \\
\text { activities }(\mu \mathrm{g} / \mathrm{mL})\end{array}$ & $\begin{array}{l}\text { Reducing power } \\
\text { activity }(\mu \mathrm{g} / \mathrm{mL})\end{array}$ & $\begin{array}{l}\text { ORAC capacity test } \\
\text { ( } \mu \mathrm{mol} \mathrm{TE} / \mathrm{mg})\end{array}$ \\
\hline Anthocyanin-rich extract of $R$. tomentosa & $6.27 \pm 0.25$ & $90.3 \pm 1.52$ & $51.7 \pm 0.74$ & $9.29 \pm 0.08$ \\
\hline Ascorbic acid & $17.4 \pm 0.31$ & $206 \pm 2.37$ & $31.3 \pm 0.93$ & $1.79 \pm 0.03$ \\
\hline
\end{tabular}

TE: Trolox equivalents, $R$. tomentosa: Rhodomyrtus tomentosa, DPPH: 1,1-diphenyl-2-picryl-hydrazyl, ORAC: Oxygen radical absorbance capacity

and nuclear lysates from RAW264.7 cells and mice, revealed that the methanolic extract of $R$. tomentosa was capable of suppressing the activation of both nuclear factor-kB and activator protein-1 pathways by directly targeting spleen tyrosine kinase/proto-oncogene tyrosineprotein kinase (Syk/Src) and interleukin-1 receptor-associated kinase 1/interleukin-1 receptor-associated kinase 4 (IRAK1/IRAK4)

\section{OSTEOGENIC ACTIVITY}

Structures of two novel compounds were determined by Tung et al. [22] to be 4,8,9,10-tetrahydroxy-2,3,7-trimethoxyanthracene-6-0- $\beta$-Dglucopyranoside and 2,4,7,8,9,10-hexahydroxy-3-methoxyanthracene6-0- $\alpha$-L-rhamnopyranoside. These compounds significantly increased the alkaline phosphatase activity, collagen synthesis, and mineralization of the nodules of MC3T3-E1 osteoblastic cells compared to those of the control, respectively. Osteoblastic differentiation is an important step in bone formation.

\section{TOXICITY}

To apply these plant extracts as topical agents for acne treatment, the cytotoxic effect of the ethanol extract and rhodomyrtone on human dermal fibroblasts was investigated by Saising and Voravuthikunchai [34]. The results demonstrated the $\mathrm{IC}_{50}$ values of the ethanol extract and rhodomyrtone were 476 and more than $200 \mathrm{mg} / \mathrm{mL}$, respectively, which is approximately 15- and 400-fold higher than their respective MIC $_{90}$ values. This result indicated that both substances had very low cytotoxicity and could, therefore, be applied as topical therapeutic anti-acne agents [34].

\section{CONCLUSION}

This review summarized the traditional uses and pharmacological activities of $R$. tomentosa based on traditional literature and modern evidence, and it provided a new foundation for further research on its mechanism of action and the development of better therapeutic antibacterial agents of rhodomyrtone isolated from $R$. tomentosa in the future. Current studies of $R$. tomentosa mostly focus on the leaves and fruits and their rich bioactive secondary metabolites, but these studies are still unclear and insufficient. Pharmacological studies using different chemical constituents from the roots, and other parts of R. tomentos $a$ are required. As recent studies have revealed that some pure chemicals and related extracts showed promising antibacterial effects, these effects need to be further proven through additional animal experiments. It is also necessary to combine studies of the biological activity with research on clinical applications that explore the material basis of their efficacy. We expect that this will be a key direction for future research. Research on these sustainable uses of this resource could be met by undertaking deep scientific studies to determine whether a single compound or a group of effective compounds would comprise the best product. It is necessary to establish programs for medicinal resource utilization and conservation of $R$. tomentosa in future studies. Although $R$. tomentosa was widely used by ancient people as a traditional medicine, we are still lacking sufficient safety information, and only a small number of toxicity studies have been conducted. Thus, further research into its toxic effects is also necessary.

Overall, R. tomentosa is a valuable herb that is worth additional attention because of its wide uses, extensive biological activities, and reliable clinical efficacy. However, the current health-related information on $R$. tomentosa is not sufficient, and its clinical value has not been sufficiently explored. The plants contain many biologically active substances, but the existing studies of these substances may be only the tip of the iceberg. Therefore, a deep and systematic phytochemical investigation of $R$. tomentosa and its pharmacological properties, especially its mechanism of action, to illustrate its ethnomedicinal use, and support further healthcare product development will undoubtedly be the focus of further research. This research will enable the improved development and utilization of ethnomedical resources.

\section{REFERENCES}

1. Cos P, Vlietinck AJ, Berghe DV, Maes L. Anti-infective potential of natural products: How to develop a stronger in vitro "proof-of-concept". J Ethnopharmacol 2006;106:290-302.

2. Bernhoft A. A brief review on bioactive compounds in plants. Bioactive Compounds in Plants-Benefits and Risks for Man and Animals. Oslow, Norway: The Norwegian Academy of Science and Letters; 2010. p. 11-7.

3. Sasidharan S, Chen Y, Saravanan D, Sundram K, Latha LY. Extraction, isolation and characterization of bioactive compounds from plants' extracts. African Journal of Tradit Complement Altern Med 2011;8(1):1-10.

4. Do T. Medicine Plants and Remedies of Vietnam. Hanoi: Thoi Dai publisher; 2011.

5. Limsuwan S, Trip EN, Kouwen TR, Piersma S, Hiranrat A, Mahabusarakam W, et al. Rhodomyrtone: A new candidate as natural antibacterial drug from Rhodomyrtus tomentosa. Phytomedicine 2009;16(6):645-51.

6. Winotai A, Wright T, Goolsby JA. Herbivores in Thailand on Rhodomyrtus tomentosa (Myrtaceae), an invasive weed in Florida. Fla Entomol 2005;88(1):104-5.

7. Lai TN, André C, Rogez H, Mignolet E, Nguyen TB, Larondelle Y. Nutritional composition and antioxidant properties of the sim fruit (Rhodomyrtus tomentosa). Food Chem 2015;168:410-6.

8. Lim T. Rhodomyrtus tomentosa. Edible medicinal and non medicinal plants. New York: Springer; 2012. p. 732-7.

9. Maskam MF. Antioxidant Effects of Rhodomyrtus tomentosa (Kemunting) Extract on the Development of Experimental 
Atherosclerotic-Induced New Zealand White Rabbit. University of Malaya; 2011.

10. Langeland KA. Identification and Biology of Nonnative Plants in Florida's Natural Areas. Gainesville, FL: IFAS Communication Services, University of Florida; 2008.

11. Latiff A. Rhodomyrtus tomentosa (Aiton) Hassk. Plant Resources of South-East Asia No. 2. Bogor: Prosea; 1992. p. 276-7.

12. Arya V. A review on anti-tuberculosis plants. Int J PharmTech Res 2011;3(2):872-80

13. Ong H, Nordiana M. Malay ethno-medico botany in Machang, Kelantan, Malaysia. Fitoterapia 1999;70(5):502-13.

14. Wei F. Manufacture of Oral Liquid Containing Traditional Chinese Medicine Extract for Treating Gynecopathy (Guangxi Huahong Pharmaceutical Co., Ltd., People's Republic of China; Shanghai Fosun Pharmaceutical (Group) Co., Ltd.), Faming Zhuanli Shenqing Gongka Shuomingshu. People's Republic of China Patent CN1846715; 2006.

15. Chuakul W. Medicinal plants in the Khok Pho district, pattani province (Thailand). Thai J Phytopharm 2005;12:23-45.

16. Jeong D, Yang WS, Yang Y, Nam G, Kim JH, Yoon DH, et al. In vitro and in vivo anti-inflammatory effect of Rhodomyrtus tomentosa methanol extract. J Ethnopharmacol 2013;146(1):205-13.

17. Wu X, Beecher GR, Holden JM, Haytowitz DB, Gebhardt SE, Prior RL. Lipophilic and hydrophilic antioxidant capacities of common foods in the United States. J Agric Food Chem 2004;52(12):4026-37.

18. Lai TN, Herent MF, Quetin-Leclercq J, Nguyen TB, Rogez H, Larondelle $\mathrm{Y}$, et al. Piceatannol, a potent bioactive stilbene, as major phenolic component in Rhodomyrtus tomentosa. Food Chem 2013;138(2-3):1421-30

19. Cui C, Zhang S, You L, Ren J, Luo W, Chen W, et al. Antioxidant capacity of anthocyanins from Rhodomyrtus tomentosa (Ait.) and identification of the major anthocyanins. Food Chem 2013;139(1-4):1-8.

20. Liu GL, Guo HH, Sun YM. Optimization of the extraction of anthocyanins from the fruit skin of Rhodomyrtus tomentosa (Ait.) Hassk and identification of anthocyanins in the extract using highperformance liquid chromatography-electrospray ionization-mass spectrometry (HPLC-ESI-MS). Int J Mol Sci 2012;13(5):6292-302.

21. Wu P, Ma G, Li N, Deng Q, Yin Y, Huang R. Investigation of in vitro and in vivo antioxidant activities of flavonoids rich extract from the berries of Rhodomyrtus tomentosa (Ait.) Hassk. Food Chem 2015; 173:194-202

22. Tung NH, Ding Y, Choi EM, Van Kiem P, Van Minh C, Kim YH. New anthracene glycosides from Rhodomyrtus tomentosa stimulate osteoblastic differentiation of MC3T3-E1 cells. Arch Pharm Res 2009;32(4):515-20.

23. Hiranrat A, Mahabusarakam W. New acylphloroglucinols from the leaves of Rhodomyrtus tomentosa. Tetrahedron 2008;64(49):11193-7.

24. Hiranrat A, Mahabusarakam W, Carroll AR, Duffy S, Avery VM Tomentosones A and B, hexacyclic phloroglucinol derivatives from the Thai shrub Rhodomyrtus tomentosa. J Org Chem 2011;77(1):680-3.

25. Salni D, Sargent MV, Skelton BW, Soediro I, Sutisna M, White AH, et al. Rhodomyrtone, an antibotic from Rhodomyrtus tomentosa. Aust J Chem 2002;55(3):229-32

26. Hiranrat A, Chitbankluoi W, Mahabusarakam W, Limsuwan S,
Voravuthikunchai S. Anew flavellagic acid derivative and phloroglucinol from Rhodomyrtus tomentosa. Nat Prod Res 2012;26(20):1904-9.

27. Fahmi R, Sargent M, Skelton B, White A. 5-Hydroxy-3, 3', 4', 5', 7-pentamethoxyflavone (combretol). Acta Crystallogr Sect E Struct Rep Online. 2004;60(1):86-8.

28. Hou A, Wu Y, Liu Y. Flavone glycosides and an ellagitannin from downy rosemyrtle (Rhodomytus tomentosa). Chin Tradit Herb Drugs 1999;30:645-7.

29. Hui WH, Li MM, Luk K. Triterpenoids and steroids from Rhodomyrtus tomentosa. Phytochemistry 1975;14(3):833-4.

30. Wai-Haan H, Man-Moon L. Two new triterpenoids from Rhodomyrtus tomentosa. Phytochemistry 1976;15(11):1741-3.

31. Liu Y, Hou A, Ji C, Wu Y. Isolation and structure of hydrolysable tannins from Rhodomyrtus tomentosa. Natl Prod Res Dev 1997;10(1):14-9.

32. Limsuwan S, Hesseling-Meinders A, Voravuthikunchai SP, Van Dijl JM, Kayser O. Potential antibiotic and anti-infective effects of rhodomyrtone from Rhodomyrtus tomentosa (Aiton) Hassk. on Streptococcus pyogenes as revealed by proteomics. Phytomedicine 2011;18(11):934-40.

33. Saising J, Hiranrat A, Mahabusarakam W, Ongsakul M, Voravuthikunchai SP. Rhodomyrtone from Rhodomyrtus tomentosa (Aiton) Hassk. as a natural antibiotic for staphylococcal cutaneous infections. J Health Sci 2008;54(5):589-95.

34. Saising J, Voravuthikunchai SP. Anti Propionibacterium acnes activity of rhodomyrtone, an effective compound from Rhodomyrtus tomentosa (Aiton) Hassk. leaves. Anaerobe 2012;18(4):400-4.

35. Voravuthikunchai SP, Dolah S, Charernjiratrakul W. Control of Bacillus cereus in foods by Rhodomyrtus tomentosa (Ait.) Hassk. leaf extract and its purified compound. J Food Prot2010;73(10):1907-12.

36. Limsuwan S, Kayser O, Voravuthikunchai SP. Antibacterial activity of Rhodomyrtus tomentosa (Aiton) Hassk. leaf extract against clinical isolates of Streptococcus pyogenes. Evid Based Complement Alternat Med 2012;2012:697183.

37. Saising J, Ongsakul M, Voravuthikunchai SP. Rhodomyrtus tomentosa (Aiton) Hassk. ethanol extract and rhodomyrtone: A potential strategy for the treatment of biofilm-forming staphylococci. J Med Microbiol 2011;60(12):1793-800.

38. Leejae S, Hasap L, Voravuthikunchai SP. Inhibition of staphyloxanthin biosynthesis in Staphylococcus aureus by rhodomyrtone, a novel antibiotic candidate. J Med Microbiol 2013;62(3):421-8.

39. Jeenkeawpieam J, Phongpaichit S, Rukachaisirikul V, Sakayaroj J. Antifungal activity and molecular identification of endophytic fung from the angiosperm Rhodomyrtus tomentosa. Afr J Biotechnol 2012;11(75):14007-16.

40. Plodpai P, Petcharat V, Chuenchit S, Chakthong S, Joycharat N, Voravuthikunchai SP. Desmos chinensis: A new candidate as natural antifungicide to control rice diseases. Ind Crops Prod 2013;42:324-31.

41. Lavanya G, Voravuthikunchai SP, Towatana NH. Acetone extract from Rhodomyrtus tomentosa: A potent natural antioxidant. Evid Based Complement Alternat Med 2012;2012:535479.

42. Geetha K, Sridhar C, Murugan V. Antioxidant and healing effect of aqueous alcoholic extract of Rhodomyrtus tomentosa (Ait.) Hassk on chronic gastric ulcers in rats. J Pharm Res 2010;3(12):2860-2. 